\title{
A INTRODUÇÃO DO GÊNERO Cichla [BLOCK E SCHNEIDER, 1801] NA PLANÍCIE DE INUNDAÇÃO DO ALTO RIO PARANÁ
}

\author{
Luciano Seraphim Gasques ${ }^{1}$ \\ Thomaz Mansini Carrenho Fabrin² \\ Sônia Maria Alves Pinto Prioli ${ }^{3}$ \\ Alberto José Prioli ${ }^{3}$
}

GASQUES, L. S.; FABRIN, T. M. C.; PRIOLI, S. M. A. P.; PRIOLI, A. J. A introdução do gênero Cichla [Block e Schneider, 1801] na planície de inundação do Alto Rio Paraná. Arq. Ciênc. Vet. Zool. UNIPAR, Umuarama, v. 17, n. 4, p. 261-266, out./dez. 2014.

RESUMO: As espécies que compõem o gênero Cichla Block e Schneider, 1801 são piscívoras, possuem grande plasticidade fenotípica e oferecem cuidados para sua prole, motivos estes que as tornam invasoras de alto impacto ambiental. O conhecimento taxonômico e da diversidade genética são importantes para o monitoramento populacional das espécies introduzidas. O objetivo deste trabalho foi caracterizar as espécies e esboçar um histórico da presença do gênero Cichla na planície de inundação do alto rio Paraná evidenciando a problemática de sua introdução nesta região. Análises de diversidade genética em populações introduzidas na bacia do rio Paraná de Cichla kelberi [Kullander e Ferreira, 2006] e C. piquiti [Kullander e Ferreira, 2006] têm demonstrado a origem dos espécimes introduzidos assim como a sua hibridação.

PALAVRAS-CHAVE: Tucunaré. Hibridação. Molecular. Espécie exotica.

\section{THE Cichla [BLOCK e SCHNEIDER, 1801] GENUS IN FLOODPLAINS OF THE UPPER PARANÁ RIVER}

ABSTRACT: The species constituting the Cichla [Block e Schneider, 1801] genus are piscivorous, present great phenotypic plasticity and provide care for their offspring, reasons that characterise these intruders as of high environmental impact. The taxonomic and genetic diversity knowledge is important for population monitoring of the introduced species. The aim of this study is to characterize the species and draw a history of the presence of the Cichla genus in the floodplain of the Upper Paraná River, showing the problems of its introduction in such region. The analyses of genetic diversity of $C$. kelberi [Kullander e Ferreira, 2006] and C. piquiti [Kullander e Ferreira, 2006] on populations introduced to the Paraná River basin have demonstrated the origin of specimens introduced as the hybridization of these two species.

KEYWORDS: Peacock Bass. Hybridization. Molecular. Exotic species.

\section{LA INTRODUCCIÓN DEL GÉNERO Cichla [BLOCK Y SCHNEIDER, 1801] EN LA LLANURA DE INUNDACIÓN DEL ALTO RÍO PARANÁ}

RESUMEN: Las especies que componen el género Cichla Block y Schneider, 1801 son piscívoras, tienen gran plasticidad fenotípica y ofrecen cuidados a su prole, motivos estos que las vuelven invasoras de alto impacto ambiental. El conocimiento taxonómico y la diversidad genética son importantes para el monitoreo poblacional de las especies introducidas. El objetivo de este trabajo ha sido caracterizar las especies y esbozar un histórico de la presencia del género Cichla en la llanura de inundación del alto Río Paraná evidenciando la problemática de su introducción en esta región. Análisis de la diversidad genética en poblaciones introducidas en la bacía del Río Paraná de Cichla kelberi [Kullander y Ferreira, 2006] y C. piquiti [Kullander y Ferreira, 2006], ha demostrado el origen de los especímenes introducidos, así como su hibridación.

PALABRAS CLAVE: Tucunaré. Hibridación. Molecular. Especie exótica.

\section{Introdução}

A América do Sul é caracterizada por uma ictiofauna abundante, sendo estimado que um quarto da biodiversidade de peixes de água doce é encontrada na América do Sul Neotropical (SCHAEFER, 1998).

Entre os vários grupos encontrados na região Neotropical um dos mais importantes é a família Cichlidae, pertencente à ordem Perciformes, apresenta espécies que vão desde pequeno até grande porte. As principais características desta família é a presença de uma linha lateral dividida em dois ramos e a boca protrátil com mobilidade no pré-maxilar.
Esta família tem sido objeto de muitas pesquisas filogenéticas (LOPEZ-FERNANDEZ et al., 2010). Membros dos Ciclídeos, os tucunarés são conhecidos internacionalmente como Peacock Bass, e são pertencentes ao gênero Cichla [Bloch e Schneider, 1801] (GRAÇA; PAVANELLI, 2007).

Os indivíduos deste gênero são piscívoros e apresentam relativamente baixos níveis de migração e de habilidade de dispersão (HOEINGHAUS et al., 2003). Entretanto existem evidências da habilidade de dispersão do macho (CARVAJAL-VALLEJOS et al., 2010; MACRANDER, 2010). Durante a reprodução apresenta como comportamento a construção de ninhos e cuidados com a prole (ZARET,

DOI: https://doi.org/10.25110/arqvet.v17i4.2014.5027

${ }^{1}$ Docente do curso de Ciências Biológicas da Universidade Paranaense, Campus Sede, Umuarama, Paraná. Praça Mascarenhas de Moraes, 4282. Umuarama/ PR. CEP 87502-210.1sgasques@yahoo.com.br

${ }^{2}$ Mestrando do programa de pós-graduação em Ecologia de Ambientes Aquáticos Continentais, Universidade Estadual de Maringá, Maringá, Paraná.

${ }^{3}$ Docente do programa de pós-graduação em Biologia Comparada, Universidade Estadual de Maringá, Maringá, Paraná. 
1980; AGOSTINHO; JÚLIO JR.; GOMES, 2003).

Nativo da bacia Amazônica, o gênero Cichla é originário de uma linhagem monofilética que contém 15 espécies descritas e amplamente distribuídas na região Neotropical. As espécies deste gênero são de grande porte e seus espécimes podem atingir até $12 \mathrm{~kg}$ sendo de importância econômica na pesca comercial e recreativa (KULLANDER; FERREIRA, 2006).

Seu caráter esportivo devido à sua agressividade quando ataca iscas artificiais, assim como a boa aceitação comercial de sua carne, tem motivado a introdução ilegal de espécies deste gênero em várias regiões do mundo e também em várias bacias hidrográficas no Brasil (WINEMILLER, 2001, AGOSTINHO et al., 2007; PELICICE; AGOSTINHO, 2009). Este fato tem ocasionado muitos problemas aos ambientes naturais uma vez que são predadores vorazes e apresentam alta plasticidade fenotípica e capacidade reprodutiva para adaptar-se às condições ecológicas adversas (CHELLAPPA et al., 2003; KOVALENKO et al., 2010). Embora a maioria das introduções tenham sido danosas, Schafland, Gesting e Stanford (2008) citam uma introdução legal e bem sucedida C. ocellaris [Schneider, 1801] na Flórida (USA), uma vez esta teve como objetivo controlar espécies introduzidas danosas à região.

De acordo com Agostinho e Júlio Jr (1996), o Brasil apresenta um elevado número de introdução de espécies no meio aquático e desta forma merece atenção especial, uma vez que a introdução de espécies tem sido considerada a segunda maior causa de extinção de espécies animais e plantas, superada apenas pelas alterações ambientais (RODRIGUEZ, 2001; WINEMILLER; TAPHORN; BARBARINO-DUQUE, 1997). Quando considerado apenas o último século, a introdução de espécies tem sido reportada como a principal causa de extinções animais (ELVIRA; ALMODÓVAR, 2001).

A prática de introdução de espécies na bacia do alto rio Paraná como uma estratégia de estoque foi comum desde 1990 (AGOSTINHO et al., 2007) e foi desenvolvida também por companhias hidroelétricas nesta região (ESPÍNOLA; MINTE-VERA; JÚLIO JR., 2010). O histórico da introdução de Cichla na bacia do alto rio Paraná, entretanto não é clara.

A estrutura da planície de inundação possui propriedades adequadas para o estabelecimento de espécies de Cichla, semelhantes ao seu ambiente original, uma vez que possui lagoas e ressacos (ambientes lênticos) compreendendo espaços amplos, água transparente e mais quentes (AGOSTINHO et al., 2004). Outra característica da planície de inundação que pode ter auxiliado neste processo é a redução das partículas presentes na água resultante dos represamentos à montante, aumentando desta forma a transparência da água (AGOSTINHO et al., 2004; ESPÍNOLA; MINTE-VERA; JÚLIO, 2010).

O objetivo deste trabalho foi caracterizar a presença das espécies do gênero Cichla na planície de inundação do alto rio Paraná, esboçando um histórico e evidenciando a problemática de sua introdução nesta região. de inundação do alto rio Paraná

Originalmente o gênero Cichla é amplamente distribuído nos rios Amazonas, Tocantins e Orinoco. No Brasil, introduções de espécies deste gênero ocorreram nas bacias dos rios Paraná, Paraguai, Paraíba do Sul e Paraguaçú (KULLANDER; FERREIRA, 2006).

Entre as 15 espécies do gênero referenciadas na revisão realizada por Kullander e Ferreira (2006), nove novas espécies foram descritas neste trabalho, sendo que destas, duas são as encontradas na planície de inundação do alto rio Paraná: Cichla kelberi [Kullander e Ferreira, 2006] e Cichla piquiti [Kullander e Ferreira, 2006].

A espécie C. kelberi, vulgarmente conhecida como tucurané amarelo, diferencia-se das demais espécies do gênero por apresentar pequenas manchas claras nas nadadeiras pélvicas e anal e no lobo inferior da nadadeira caudal nos adultos (Figura 1).

Como a primeira identificação dos espécimes da planície de inundação ocorreu anteriormente à revisão do gênero realizada por Kullander e Ferreira (2006), os espécimes de C. kelberi na planície de inundação do alto rio Paraná foram erroneamente identificados como C. monoculus [Agassiz, 1831], por assemelhar-se ao formato e coloração geral desta espécie. É importante ressaltar que nesta época havia apenas cinco espécies válidas identificadas: $C$. temensis [Humboldt, 1821], C. monoculus, C. ocellaris, C. orinocensis [Humboldt, 1821] e C. intermedia [Machado-Allison, 1971] (KULLANDER, 1986). Embora não presente na planície de inundação do alto rio Paraná, a espécie Cichla monoculus é documentada em outras regiões da bacia do alto rio Paraná a montante, como por exemplo na represa de Capivara, Taquaruçu e Rosana (BRIÑEZ et al., 2013) e a sua introdução, através de escapes de tanques do rio Tibagi é bem documentada (ORSI; AGOSTINHO, 1999).

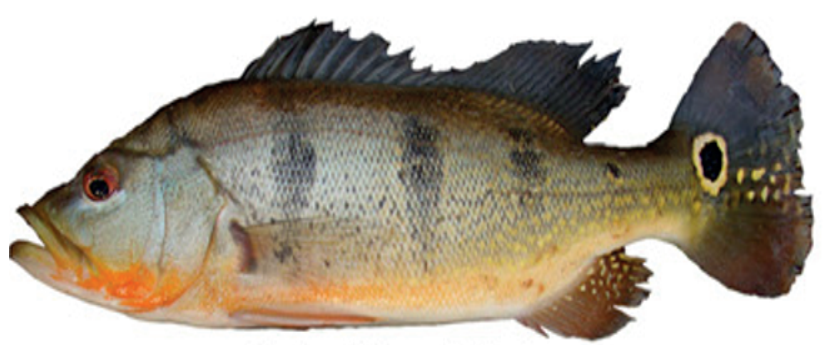

Figura 1: Cichla kelberi Kullander e Ferreira, 2006 (fonte: WILLIS et al., 2012).

A segunda espécie presente na planície de inundação, C. piquiti, é conhecida localmente como tucunaré azul, e tem sua diferenciação evidenciada pela combinação de 89 a 98 escamas na linha lateral superior e no padrão de coloração no adulto que inclui cinco ou mais faixas verticais escuras abaixo da nadadeira dorsal (Figura 2). Anteriormente à sua descrição por Kullander e Ferreira (2006), foi identificada como Cichla sp. (KULLANDER; FERREIRA, 2006; GRAÇA; PAVANELLI, 2007).

\section{Desenvolvimento}




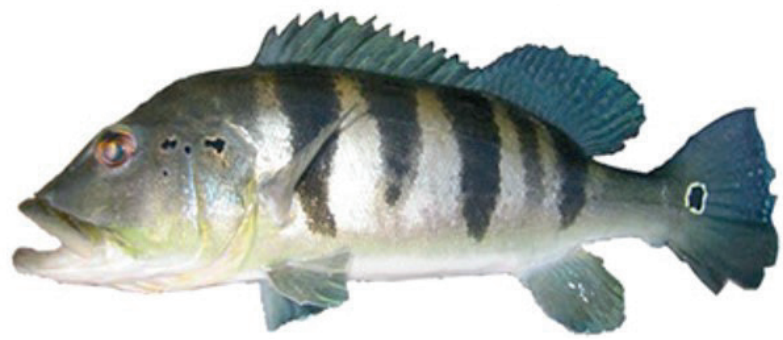

Figura 2: Cichla piquiti [Kullander e Ferreira, 2006] (fonte: WILLIS et al., 2012).

Espécimes do gênero Cichla estão entre os mais abundantes na planície de inundação do alto rio Paraná (AGOSTINHO; JÚLIO JR.; GOMES, 2003; 2004; JÚLIO Jr; AGOSTINHO, 2003). Os primeiros espécimes de tucunaré foram relatados em 1985, permanecendo por algum tempo com baixa densidade. Sua ampla distribuição foi associada, principalmente, às mudanças da transparência da água ocasionadas pela construção das barragens a montante (ABUJANRA, 2007)

Análises genéticas de populações de Tucunaré nas áreas invadidas na planície de inundação do alto rio Paraná, entretanto, confirmaram a hipótese de múltiplas introduções de espécimes das diferentes regiões em diferentes pontos da bacia (BRIÑEZ et al., 2013; OLIVEIRA et al., 2006).

\section{O impacto do gênero Cichla na planície de inundação do alto rio Paraná}

As espécies que compõem o gênero Cichla, quando introduzidas em ambientes exóticos, apresentam alto grau de impacto ambiental em função das suas características. São piscívoras vorazes, possuem grande plasticidade fenotípica para adaptação a novos ambientes, durante a reprodução nidificam e apresentam cuidado parental com sua prole (CHELLAPPA et al., 2003; KOVALENKO et al., 2010).

Sunaga e Verani (1997) em estudos abrangendo lagos do vale do Rio Doce em que C. monoculus foi introduzido relatam que o aumento da biomassa dessa espécie é acompanhado de um decréscimo de espécies de peixes. Uma estimativa deste impacto foi realizada por Pelicice e Agostinho (2009) que avaliaram a introdução de tucunarés no reservatório de Rosana na Bacia do rio Paraná. Em seus resultados detectaram uma forte redução $(95 \%)$ na densidade de peixes nativos e (80\%) na riqueza de espécies dos peixes associados às macrófitas aquáticas. O período de estudos compreendeu os anos de 2003 a 2007, período em que ocorreu a introdução do gênero Cichla neste reservatório (2004).

Para a avaliação dos impactos ambientais é fundamental verificar o conhecimento taxonômico e a diversidade genética das espécies. Isto se faz necessário, pois a avaliação do desempenho das espécies neste ambiente depende da identificação dos espécimes locais, do acompanhamento do tamanho da população e da análise da variabilidade genética. Quanto maior a taxa de variabilidade genética intraespecífica das espécies invasoras em seu novo ambiente, maiores serão as chances de sucesso de adaptação destas (FUTUYMA, 2003, SNUSTAD; SIMONS, 2001).

\section{A Hibridação entre espécies do gênero}

A hibridação interespecífica é considerada um fenômeno comum entre vários grupos de peixes de água doce, e este fenômeno está geralmente relacionado com os fatores ambientais que são decrescentes gradualmente do norte temperado para o Sul tropical. A frequência da hibridação é inversamente relacionada ao número de espécies em determinadas áreas. Desse modo, na Amazônia onde há uma alta diversidade, a frequência de hibridação tende a ser menor (HUBBS, 1955). Entretanto, existem muitos relatos de híbridos de peixes nestas regiões (RIBEIRO, 1985; TEIXEIRA; OLIVEIRA, 2005).

Eventos de hibridação em espécies introduzidas têm sido relatadas para espécies, geneticamente, compatíveis com espécies locais (ARTHINGTON, 1991; BRINN; PORTO; FELDBERG, 2004)

As alterações dos ambientes e a introdução de espécies possuem grande influência no processo evolutivo. Este fenômeno ocorre devido à pressão seletiva exercida sobre os espécimes sujeitos à nova condição ambiental (FUTUYMA, 2003). Em referência a adaptação e a especiação das espécies do gênero Cichla, sua localização originária restrita à bacia Amazônica permite inferir que os dois principais mecanismos de especiação para este gênero tenham sido a especiação simpátrica e parapátrica.

$\mathrm{Na}$ região Amazônica, a criação do reservatório da usina Hidroelétrica de Balbina tem sido associada a um processo de hibridação das espécies $C$. monoculus e $C$. temensis. A alteração do ambiente por meio do alagamento e da nova geografia da região findou o isolamento geográfico, possibilitando dessa maneira a hibridação destas duas espécies afetando, sobretudo o processo de especiação e o aumento da diversidade genética para estes espécimes (ANDRADE et al., 2001; BRINN; PORTO; FELDBERG, 2004). O padrão híbrido foi encontrado em um espécime identificado como C. temensis coletado na hidroelétrica de Balbina. A explicação possível é que as duas espécies se intercruzam em outras regiões de simpátria. É esperada também a possível hibridação entre outras espécies de Cichla com C. monoculus, que no entanto não foram encontradas (TEIXEIRA; OLIVEIRA, 2005).

$\mathrm{Na}$ bacia do rio Paraná, Oliveira et al. (2006) investigaram a diversidade genética de populações de $C$. monoculus e Cichla sp., depois confirmadas como C. kelberi e C. piquiti respectivamente por Kullander e Ferreira (2006), e demonstraram um padrão de diferenciação genética com indivíduos geneticamente intermediários entre as duas espécies indicando uma forte evidência da quebra do isolamento reprodutivo destas duas espécies, e deste modo resultando no híbrido. Embora na sub-bacia do Tocantins Araguaia as duas espécies estudadas sejam nativas e coexistam, não existem relatos deste fenômeno. Outra hipótese levantada neste trabalho é que, a maior prevalência destes espécimes híbridos é um forte indicativo de que estes sejam férteis.

Visando a comprovar o processo de hibridação, Oliveira et al. (2008) verificaram o polimorfismo da região não transcrita do gene rRNA $5 \mathrm{~S}$ em busca de um marcador eficiente para a identificação dos híbridos. No entanto, este procedimento para essas espécies não se mostrou eficiente por não apresentar um padrão de bandas espécie-específica 
para estas duas espécies.

\section{Implicações da Hibridação entre as espécies}

A hibridação é um processo comum entre muitas espécies de peixes. O retrocruzamento com os parentais é um fenômeno que quando ocorre pode levar a introgressão de genes. Este também é um aspecto corriqueiro entre diferentes linhagens de peixes, particularmente quando espécies alopátricas são introduzidas em novos habitats (HUBBS, 1955; AVISE et al., 2002; RUBIDGE; TAYLOR, 2004).

O maior problema da introgressão é que o fluxo gênico ininterrupto e a diferença genética entre as populações devem decrescer ao mesmo tempo sendo substituída por grandes populações mais homogêneas. Eventos de hibridação entre espécies exóticas, muitas vezes com a introgressão dos genes podem ter sérias implicações resultando em diferenças ecológicas e na perda da biodiversidade, culminando na alteração dos ecossistemas de água doce. Neste sentido, estudos de ecologia e biologia das espécies de Cichla da planície de inundação do alto rio Paraná são necessários para elucidar os impactos das populações exóticas na região e suas relações com outras populações nativas.

Oliveira et al. (2006) sugerem que as duas espécies não encontraram maiores restrições no novo habitat uma vez que nos ambientes lênticos distribuíram-se rapidamente e o novo meio "contribuiu" para a hibridação entre as espécies.

Willis et al. (2012) estudaram a hibridação interespecífica entre diversas espécies do gênero Cichla da região norte da América do Sul (Bacias do Amazonas, Tocantins-Araguaia e do Orinoco) usando dados multilocus. Nesta investigação não foram encontras evidências da introgressão de genes entre $C$. kelberi e $C$. piquiti e na genealogia mitocondrial as duas espécies encontram-se em clados diferentes.

Smith, Konings e Kornifiekd (2003) discutem as vantagens adaptativas da hibridação introgressiva no aumento da variabilidade genética entre os ciclídeos para o processo adaptativo, entretanto, é necessário ressaltar que este processo pode levar a extinção de espécies locais (PERRY; LODGE; FEDER, 2002), pois a existência de híbridos férteis deve conter uma maior variabilidade genética, e deste modo apresentar maior vigor e capacidade adaptativa, podendo desta forma, serem mais competitivos e agressivos que as espécies originais (ARTHINGTON, 1991).

Híbridos viáveis causam maior impacto que híbridos estéreis uma vez que podem cruzar ou retrocruzar entre eles podendo contribuir para um aumento da diversidade genética das espécies (BERNATCHEZ et al., 1995).

Observando genealogia mitocondrial reconstruída por Willis et al. (2010) as espécies C. monoculus e C. kelberi são muito mais próximas que $C$. kelberi e $C$. piquiti apresentando-se em um mesmo clado. Dessa forma, a introdução desta espécie ou chegada por ocupação sequencial como proposto por Briñez et al. (2013) poderia aumentar ainda mais a variabilidade genética nesta região, uma vez que o cruzamento com $C$. kelberi seria plausível, incrementando assim as relações introgressivas para estas espécies nesta região.

Análises moleculares das espécies da planície de inundação do alto rio Paraná e inferências

Oliveira et al. (2006) realizaram análise de polimorfismo através de RAPD com os primers $O P W-04, O P W-09$,
$O P W-17, O P W-19, O P A-06, O P E-09, O P X-05$ E $O P X-18$ e sequenciamento da região controle $(\mathrm{CR})$ do DNA mitocondrial. O padrão encontrado de diferenciação genética indicou a quebra do isolamento reprodutivo entre as duas espécies resultando na hibridação. A baixa frequência dos parentais na população reforça esta hipótese. O polimorfismo encontrado no mtDNA confirmou a hipótese de múltiplas introduções na bacia do Paraná. Os espécimes de C. monoculus analisados do reservatório de Capivara apresentaram como origem as populações da bacia do rio Amazonas, enquanto os da planície de inundação e do reservatório de Itaipu (C. kelberi e $C$. piquiti) são provenientes de populações nativas da bacia do rio Tocantins-Araguaia. Apontam ainda a introdução de uma subpopulação de $C$. piquiti no reservatório de Promissão.

Oliveira et al. (2008), objetivando padronizar a utilização da região NTS do 5S (DNA nuclear) em Cichla utilizaram espécimes da planície de inundação do alto rio Paraná e do rio Paranapanema, contudo, este marcador não se mostrou eficiente para distinção das duas espécies presentes na planície de inundação. Os resultados encontrados reforçaram os dados de Oliveira et al. (2006) confirmando a origem da introdução.

Almeida-Ferreira et al. (2011) utilizaram marcadores do tipo SPAR (Single Primers Amplifications Reactions) visando o entendimento da quebra dos mecanismos de isolamento e procurando evidências de introgressão dos genes nucleares em ambas as espécies de Cichla introduzidos na bacia do rio Paraná. O baixo número de espécimes parentais contrastam com o grande número de híbridos encontrado das duas espécies reforçando o fato da quebra do isolamento reprodutivo. Os marcadores utilizados confirmam a hibridação entre $C$. kelberi e $C$. piquiti na planície de inundação do alto rio Paraná, no entanto, não foi possível evidenciar os mecanismos de quebra do isolamento reprodutivo.

Briñes et al. (2013) utilizaram as sequências da região controle (CR) do DNA mitocondrial para identificar as espécies introduzidas nos reservatórios do rio Paranapanema e alto rio Paraná, identificando C. monoculus coletados nos reservatórios do rio Paranapanema a montante da planície de inundação do alto rio Paraná, assim como C. kelberi na própria planície. A pesquisa indica a presença de $C$. kelberi no reservatório de Taquaruçu, antes não relatado, sugere também a dispersão de $C$. monoculus para os reservatórios a jusante do reservatório de Capivara por ocupação sequencial.

Observando genealogia mitocondrial reconstruída por Willis et al. (2012) as espécies $C$. monoculus e $C$. kelberi são muito mais próximas que $C$. kelberi e $C$. piquiti apresentando-se em um mesmo clado.

\section{Considerações Finais}

Considerando um panorama de ocupação sequencial de $C$. monoculus, seu possível estabelecimento na planície de inundação do alto rio Paraná e a sua proximidade filogenética com $C$. kelberi é possível imaginar que caso aconteça a chegada deste gênero na planície de inundação do alto rio Paraná. Neste caso, se as barreiras reprodutivas não estiverem presentes e exista compatibilidade genética entre estas espécies, novas configurações de hibridação não descritas para o gênero Cichla poderiam ocorrer.

Os híbridos férteis devem incrementar a introgres- 
são genética, aumentando ainda mais a variabilidade genética da população nesta região, o que poderia levar a uma vantagem adaptativa dos indivíduos desta população em relação aos demais predadores nativos e espécies parentais presentes na planície de inundação. Este fato agravaria ainda mais o problema de redução da biodiversidade local ocasionada da introdução.

Dessa forma, é de fundamental importância o levantamento de dados genéticos que possam identificar as espécies presentes na planície, assim como, a hibridação entre as diferentes espécies presentes na planície.

\section{Referências}

ABUJANRA F. Influências do controle de nível e transparência da água imposta pela formação do reservatório do Porto Primavera sobre peixes de diferentes categorias do alto rio Parará. Tese. Doutorado em Ecologia de ambientes aquáticos - Departamento de Biologia, Universidade Estadual de Maringá, 2007.

AGOSTINHO, A. A. et al. Fish Assemblage. In: THOMAZ, S. M., AGOSTINHO, A. A.; HAHN, N. S. The Upper Paraná River and its Floodplain: Physical Aspects, Ecology and Conservation, p. 223-246. Leiden: Backhuys Publishers, 2004

AgOstinho A. A.; GOMES L. C.; PELICICE F. $M$. Ecologia e manejo de recursos pesqueiros em reservatórios no Brasil. Eduem. Maringá, 2007. 501 p.

AGOSTINHO, A.A.; JULIO JR, H.F. Ameaça ecológica: peixes de outras águas. Ciência Hoje, v. 21 n. 124 p. 36-44, 1996

AGOSTINHO, A. A.; JÚLIO JR., H. F. JR; GOMES, L. C. Allochthonous species in the Upper Parana basin: status and patterns. In VOGT, R. C.; CHAO, N. L. Joint Meeting of Ichthyologists and Herpetologists, Abstracts. American Society of Ichthyologists and Herpetologists: (ASIH), p. 5. Manaus, AM, 2003.

ARTHINGTON, A. H. Ecological and genetic impacts of introduced and translocated freshwater fishes in Australia. Canadian Journal of Fisheries and Aquatic Sciences, v. 48, n. 1, p. 33-43, 1991.

ALMEIDA-FERREIRA, G. C. et al. Spar genetic analysis of two invasive species of Cichla (Tucunaré) (Perciformes: Cichlidae) in the Paraná river basin. Acta Scientiarum. Biological Sciences, v. 33, n. 1, p. 79-85, 2011.

ANDRADE, F. et al. Análise filogenética de duas espécies de Tucunaré (Cichla, Perciformes), com o registro de hibridação em diferentes pontos da bacia amazônica.

Revista Virtual de Iniciação Acadêmica da UFPA, 1:1, $1-11,2001$.

AVISE, J. C. et al. Genetic mating systems and reproductive natural histories of fishes: lessons for ecology and evolution. Annual Review of Genetics, v. 36, p. 19-45, 2002.
BERNATCHEZ, L. et al. Introgression and fixation of Arctic char (Salvelinus alpinus) mitochondrial genome in an allopatric population of brook trout (Salvelinus fontinalis). Canadian Journal of Fisheries and Aquatic Sciences, v. 52, n. 1, p. 179-185, 1995.

BRIÑEZ, B. et al. Molecular identification of Cichla (Perciformes: Cichlidae) introduced in reservoirs in Southern Brazil. Acta Scientiarum Biological Sciences, v. 35, n. 2, p. 233-239, 6 maio 2013.

BRINN, M. N. A., PORTO, J. I. R., FELDBERG, E. Kariological evidence for hibridization between Cichla monoculus and Cichla temensis (Perciformes, Cichlidae) in the Amazon. Hereditas, v. 141, p. 252-257, 2004.

CARVAJAL-VALLEJOS, F. M. et al. Population genetic structure of Cichla pleisona (Perciformer: Cichlidae) in the Upper Madera basin (Bolivian Amazon): Sex biased dispersal? Molecular Phylogenetics and Evolution, v. 57, p. 1334-1340, 2010.

CHELLAPPA, S., CÂMARA, M. R.; CHELLAPPA N. T. Ecology of Cichla monoculus (Osteichthyes: Cichlidae) from a reservoir in the semi-arid region of Brasil.

Hidrobiologia, v. 504, p. 267-273, 2003.

ESPÍNOLA, L. A.; MINTE-VERA, C. V.; JÚLIO, H. F. Invasibility of reservoirs in the Paraná Basin, Brazil, to Cichla kelberi Kullander and Ferreira, 2006. Biological Invasions, v. 12, n. 6, p. 1873-1888, 2010.

FUTUYMA, D. J. Biologia evolutiva. 2ed. FUNPEC. Ribeirão Preto, 2003. 631p.

GRAÇA, W. J., PAVANELLI, C. S. Peixes da planície de inundação do alto rio Paraná e áreas adjacentes. EDUEM. Maringá, 2007. 241p.

HUBBS, C. L. Hibridization between fish species in nature. Systematic Zoology, v. 4, p. 1-20, 1955.

HOEINGHAUS, D. L. et al. Spatiotemporal variation in fish assemblage structure in tropical creeks. Enviromental Biology Fishes, v. 67, p. 379-387, 2003.

JULIO JUNIOR, H. F.; AGOSTINHO, A. A. Introduced species into the Upper Parana floodplain by elimination of a geographical barrier and stocking programs. In: Joint Meeting of Ichthyologists and Herpetologists, Manaus, 2003.

KOVALENKO, K. E. et al. Recognition of non-native peacock bass, Cichla kelberi by native prey: testing the naiveté hypothesis. Biological Invasions, v. 12, n. 9, p. 3071-3080, 2010.

KULLANDER, S. O. Cichlid fishes of Amazon River Drainage of Peru. Swedish Museum of Natural History, Stockholm, Sweden, 1986. 421 p. 
KULLANDER, S.; FERREIRA, E. A review of the South American cichlid genus Cichla, with descriptions of nine new species (Teleostei: Cichlidae). Ichthyological Exploration of Freshwaters, v. 17, n. 4, p. 289-398, 2006.

LÓPEZ-FERNÁNDEZ, H.; WINEMILLER, K. O.; HONEYCUTT, R. L. Multilocus phylogeny and rapid radiations in Neotropical cichlid fishes (Perciformes: Cichlidae: Cichlinae). Molecular phylogenetics and evolution, v. 55, n. 3, p. 1070-1086, 2010.

MACRANDER, J. C. Microsatellite development, population structure and demographic histories for two species of amazonian peacock bass Cichla temensis and Cichla monoculus (Perciforme: Cichlidae). University of Nebrasca - Lincon, 2010.

OLIVEIRA, A. V. et al. Genetic diversity of invasive and native Cichla (Pisces: Perciformes) populations in Brazil with evidence of interspecific hybridization. Journal of Fish Biology, v. 69, n. sb, p. 260-277, 2006.

OLIVEIRA, V. F. et al. Obtaining 5S rDNA molecular markers for native and invasive Cichla populations (Perciformes - Cichlidae), in Brazil. Acta Scientiarum Biological Sciences, v. 30, n. 1, p. 83-89, 2008.

ORSI, M. L.; AGOSTINHO, Â. A. Introdução de espécies de peixes por escapes acidentais de tanques de cultivo em rios da Bacia do Rio Paraná, Brasil. Revista Brasileira de Zoologia, v. 16, n. 2, p. 557-560, 1999.

PELICICE, F. M., AGOSTINHO, A. A. Fish fauna destruction after the introduction of a non-native predator (Cichla kelberi) in a Neotropical reservoir. Biologial Invasions, v. 11, p. 1789-1801, 2009.

PERRY, W. L.; LODGE, D. M.; FEDER, J. L. Importance of hybridization between indigenous and nonindigenous freshwater species: an overlooked threat to North American biodiversity. Systematic Biology, v. 51, p. 255-275, 2002.

RIBEIRO, M. C. L. B. A natural hybrid between two tropical fishes: Semaprochilodus insignius vs Semaprochilodus taeniurus (Teleostei, Caracoidei, Prochilodontidae). Revista Brasileira de Zoologia, v. 2, p. 419-421, 1985.

RODRIGUES, J. P. Exotic especies introductions into South America: an underestimated threat? Biodiversity and Conservation, v. 10, p. 1983-1996, 2001.

RUBIDGE, E. M.; TAYLOR, E. B. Hybridization zone structure and the potential role of selection in hybridizing populations of native westlope cutthroat trout (Oncorhynchus clarki lewisi) and introduced rainbow trout. Molecular Ecology, v. 13, p. 3725-3749, 2004.

SCHAEFER, S. A. Conflict and resolution: impact of the new taxa on phulogenetic studies of neotropical cascudinos (Siluroidei: Loricariidae). In: MALABARBA, L. R. REIS,
R. E., VARI, R. P., LUCENA Z. M. S. LUCENA, C. A. S. Phylogenetic Classification of Neotropical Fishes. p. 375400, Edipucrs, Porto Alegre, Brasil, 1998.

SCHAFLAND, P. L.; GRESTRING, K. B.; STANFORD, M. S. Florida's exotic freshwaters fishers. Florida Scientist, v. 71, n. 3, p. 220-224, 2008.

SMITH, P. S.; KONINGS, A. D.; KORNIFIELD, I. Hybrid origon of a cichid population in lake Malawi: Implications for genetic variation and species diversity. Molecular Ecology, v. 12, p. 2497-2504, 2003.

SNUSTAD, P.; SIMMONS, M. J. Fundamentos de Genética. 2ed. Rio de Janeiro, Guanabara Koogan, 2001. $756 \mathrm{p}$.

SUNAGA, T.; VERANI, J. R. The fish communities of lakes. In: TUNDISIM J. G.; SAIJO Y. Limnological studies on the rio Doce Valley lakes, Brazil. Academia Brasileira de Ciências. Universidade de São Paulo p. 359$369,1997$.

TEIXEIRA, A. S.; OLIVEIRA, S. D. S. Evidence for a natural hybrid of peacock bass (Cichla monoculus vs Cichla temensis) based on esterase electrophoretic patterns. Genetics and Molecular Research, v. 4, n. 1, p. 74-83, 2005.

WILLIS, S. C. et al. Systematics, biogeography, and evolution of the Neotropical peacock basses Cichla (Perciformes: Cichlidae). Molecular phylogenetics and evolution, v. 44, n. 1, p. 291-307, 2007.

WILLIS, S. C. et al. The Casiquiare river acts as a corridor between the Amazonas and Orinoco river basins: biogeographic analysis of the genus Cichla. Molecular ecology, v. 19, n. 5, p. 1014-30, 2010.

WINEMILLER, K. O. Ecology of peacock cichlids (Cichla spp.) in Venezuela. Journal of Aquiculture and Aquatic Sciences, v. 9, p. 93-112, 2001.

WINEMILLER, K. O.; TAPHORN, D. C.; BARBARINODUQUE, A. Ecology of Cichla (Cichlidae) in two blackwater rivers of Southern Venezuela. Copeia, v. 4, p. 690-696, 1997.

ZARET, T. M. Life history and growth relationships or Cichla ocellaris, a predatory South American cichid.

Biotropica. V. 12, p. 144-157, 1980.

Recebido em: 19/12/2013 Aceito em: 29/12/2014 